\title{
CONCEPÇÕES SOBRE EDUCAÇÃO INTEGRAL: O PROGRAMA MAIS EDUCAÇÃO DE DOURADOS-MS - 2015 EM FOCO
}

\author{
CONCEPTIONS OF INTEGRAL EDUCATION: THE MORE EDUCATION \\ PROGRAM - 2015 IN FOCUS
}

Elenir Alves Costa Gauna ${ }^{1}$

\begin{abstract}
RESUMO: As proposições de educação integral não são novas na discussão educacional brasileira, porém com a aprovação do Plano Nacional e Educação (PNE) 2014-2024, estabeleceu-se novas perspectivas para as políticas públicas da área, uma vez que se definiu a meta de atingir o mínimo de 50\% das escolas funcionando em tempo integral. Diante do desfio posto por esta meta esta investigação se debruça sobre o Programa "Mais Educação" implantado no Município de Dourados sob indução do governo federal. Para atingir esse objetivo inicialmente realizamos pesquisa bibliográfica e documental buscando apreender os fundamentos que subsidiam o programa e o conceito de educação integral que o embasa, na sequencia elaboramos a segunda fase da pesquisa, constituída de questionários aplicados aos profissionais de três escolas objetivando captar as concepções que embasam a experiência em análise. Após analisar os dados coletados observamos que o programa apresenta uma concepção restrita de educação integral, que se assenta na ampliação da jornada, para oferecer atividades para uma parcela dos alunos escolhidos por critérios de vulnerabilidade social, ou baixo rendimento escolar, ficando distante da ideia de uma educação para uma formação integral com qualidade para todos.
\end{abstract}

Palavras-chave: Educação integral. Programa Mais Educação. Contra-turno escolar.

\begin{abstract}
The comprehensive education proposals are not new in Brazilian educational discussion, but with the approval of the National and Education Plan (PNE) 2014-2024, set up new perspectives for public policies in this area, since it set the goal of achieving minimum of $50 \%$ of schools working full time. Faced with the challenge posed by this goal this research focuses on the program "More Education" implemented in the municipality of Dourados induction under the federal government. To achieve this goal initially conducted literature and documentary seeking to understand the foundations that support the program and the concept of integral education that underlies in the sequence we developed the second phase of the research consisted of questionnaires given to professionals from three schools aiming to capture the views that support the experience in analysis. After analyzing the data collected we observe that the program has a limited conception of integral education, which is based on the expansion of the journey, to offer activities for a portion of students chosen by social vulnerability criteria, or poor school performance, getting away from the idea education for an integral formation with quality for all.
\end{abstract}

Keywords: Integral education. More education program. Afterschool.

\footnotetext{
${ }^{1}$ Pedagogia, Universidade Federal da Grande Dourados. E-mail: gaunaelenir@gmail.com
} 


\section{Introdução}

Historicamente a escola no Brasil se constitui como um espaço de exclusão, destinado a poucos, tema recorrente na produção sobre a temática, tratada a partir de diferentes abordagens e com diferentes referenciais teóricos, Cavaliere (2002) destaca que a ação da escola era uma expansão linear dos processos integradores da comunidade sociocultural homogênea que a ela tinha acesso. O que se transforma á medida que se amplia o processo de escolarização, com a massificação do ensino, com uma escola que se esvaziou das responsabilidades entre outros fatores devido às instalações precárias de seu ambiente físico, pela redução da jornada e multiplicação dos turnos, pela desorientação didático-pedagógica e pela baixa qualidade da formação dos professores. Igualmente Beisiegel (2007) destaca que o processo mais marcante da escolarização no Brasil durante o século XX, foi sua contínua ampliação com a democratização do acesso, acompanhada de uma crescente sensação de crise educacional. Chegamos, portanto, ao final do século XX com um processo de crescente percepção de crise nos sistemas educacionais que trouxe diferentes propostas de reformas para solucionar esses problemas.

No contexto atual a aprovação do Plano Nacional da Educação (BRASIL/PNE, 2014), por meio da Lei $\mathrm{n}^{\circ} 13.005$ de 2014, estabeleceu-se novos desafios para as políticas públicas educacionais em relação especificamente às escolas de tempo integral, uma vez que em sua meta seis a lei determina a obrigatoriedade de "oferecer educação em tempo integral em, no mínimo, $50 \%$ (cinquenta por cento) das escolas publicas, de forma atender, pelo menos, $25 \%$ (vinte e cinco por cento) dos(as) alunos(as) da educação básica" (BRASIL, 2014). Colocouse, dessa forma, a educação integral de forma mais presente na agenda de debate das políticas públicas educacionais. Variados enfoques se apresentaram nas novas experiências, com múltiplas formas de organização curricular, diferentes arranjos para contratação dos profissionais necessários para atender a esta demanda o que em resumo define variadas concepções sobre o significado dessas experiências. Algumas iniciativas nas redes estaduais e municipais são formuladas localmente, muitas, porém, decorrem da indução do governo federal, por meio de financiamento e de regulamentação nacional.

Neste texto discutimos rapidamente alguns significados para conceito de educação integral historicamente construído, e analisamos o Programa "Mais Educação" do governo federal com ênfase em sua execução no município de Dourados. Esse trabalho é resultado de pesquisa desenvolvida junto à Rede Municipal de Educação Básica de Dourados, com o intuito de investigar o funcionamento do Programa Mais Educação, concebido pelo governo 
federal como uma forma de ampliar a jornada integral, por meio de parcerias com as redes municipais e estaduais. Interessava-nos investigar e identificar os princípios de funcionamento e as concepções que embasam o Programa, em sua formulação pelo governo federal e em sua implantação na rede municipal.

Para isso nos baseamos em pesquisa documental e bibliográfica sobre o conceito de educação integral e sobre o Programa "Mais Educação", complementada pela aplicação de questionário aos docentes de três escolas da rede municipal, envolvendo nove monitores e seis docentes (três diretores e três coordenadores do programa nas instituições) envolvidos no projeto.

O texto foi organizado em quatro partes, na primeira introduzimos a discussão sobre o conceito de educação integral, em seguida apresentamos algumas iniciativas de implantação da educação integral no Brasil e a normatização sobre o tema, na terceira parte apresentamos a normatização federal que regulamente a implementação do Programa "Mais Educação", ao final apresentamos os dados empíricos sobre o programa no município de Dourados.

\section{Apontamentos sobre o conceito de educação integral}

Historicamente existiram várias iniciativas, em geral restritas, de implantar experiência de Educação Integral, pesquisadores relatam como educadores e estudiosos lutaram para implantação da educação integral no Brasil. Segundo as Matrizes da Educação Integral pesquisada por Jaqueline Moll (2012) a educação integral ou educação integrada foi introduzida no debate nacional a partir de 1932 pelos Pioneiros da educação nova, o escolanovismo brasileiro, inspirados nos escritos de John Dewey. Vários educadores redigiram um manifesto à nação conclamando por uma escola pública, laica, obrigatória e gratuita que tivesse como preocupação a formação integral de todo cidadão. Em 1950, Anísio Teixeira um dos principais nomes do escolanovismo brasileiro, implantou o Centro Educacional Carneiro Ribeiro um projeto arquitetônico para abrigar as atividades pensadas para esse projeto de educação integral e de atendimento em tempo integral as "escolas parques" na Bahia, sendo interrompido com a ditadura militar em 1964. Partia do princípio de que:

Não se pode conseguir essa formação em uma escola por sessões, com curtos períodos letivos que hoje tem a escola brasileira. Precisamos restituir-lhes o programa com atividades práticas, dar-lhes amplas oportunidades de formação de hábitos de vida real, organizando a escola como miniatura da comunidade, com toda a gama de suas recreações e de arte. (TEIXEIRA, 1994, p. 63). 
Porém, existe certa confusão em torno do conceito de Educação Integral e de escola de tempo integral. Educação Integral em sua essência e qualidade é aquela que forma o ser humano em sua integralidade e para sua emancipação. Construir uma educação que emancipe e forme em uma perspectiva humana que considere suas múltiplas dimensões e necessidades educativas é a grande estratégia de melhoria da qualidade de ensino e promoção do sucesso escolar, que é a Educação Integral.

Reside nesse ponto a diferença entre a educação integral e uma escola de tempo integral; para essa o componente da ampliação da jornada escolar caracteriza sua centralidade, mantêm-se a mesma organização fragmentada dos processos educativos e o distanciamento entre a escola, e a comunidade, enquanto que naquela outros elementos como: a ampliação do currículo com a valorização dos saberes populares, a gestão democrática, a participação de outros sujeitos e a extensão do território educativo, tudo isso é articulado com o Projeto Político Pedagógico da escola, visando garantir a vivência escolar de alunos, professores, família e comunidade em um exercício cotidiano e coletivo de cidadania. Uma Educação integral, portanto, ultrapassa

[...] a mera ampliação de tempos, espaços e oportunidades educacionais e busca discutir e construir em nossas escolas espaços de participação, favorecendo a aprendizagem na perspectiva da cidadania, da diversidade e do respeito aos direitos humanos. O desafio é grande, mas as possibilidades de concretização da escola integral, entendendo-a como solo fértil de uma educação democrática e de qualidade social, é real. (SEDF, 2013, p. 1).

Segundo Gonçalves (2009), o conceito mais tradicional encontrado para a definição de educação integral é aquele que considera o sujeito em sua condição multidimensional, não apenas na sua dimensão cognitiva, como também na compreensão de um sujeito que é sujeito corpóreo, tem afetos e está inserido num contexto de relações. "Isso vale dizer a compreensão de um sujeito que deve ser considerado em sua dimensão biopsicossocial" (GONÇALVES, 2009, p. 3).

Conforme afirma Gadotti (2009), o princípio geral de educação integral é, evidentemente, o da integralidade. O conceito de integralidade refere-se à base da educação, que deve ser integral, unilateral e não parcial e fragmentada. Uma educação integral é educação com qualidade social cultural. Não se trata apenas de estar na escola em horário integral, mas de ter a possibilidade de desenvolver todas as potencialidades humanas que desenvolvem o corpo, a mente, a sociabilidade, a arte, a cultura, a dança, a música, o esporte, o lazer etc. 
Oferecer uma educação de qualidade não simplesmente transferir conhecimento, mas valorizar o lúdico, o brincar, a corporeidade e resgatar e conhecer diferentes culturas, pois você pode a prender e ensinar muito através de uma simples brincadeira. Mas para que aconteça esse tipo de educação tão sonhada pelos estudiosos do passado, a educação precisa dar um passo avançado que seria transformar a educação integral em uma política de Estado

Para Gadotti (2009, p. 38), a educação integral deve acontecer em todos os cantos, em diferentes espaços tempos e durante toda a vida, "estamos sempre aprendendo e ensinando, educando e nos educando [...]" a educação integral não é apenas transferências de conhecimento, mas é brincar, valorizar o lúdico, a corporeidade é resgatar reconhecer e valorizar as diferentes culturas. A permanência na escola em tempo integral deve proporcionar estudos complementares e atividades de esporte, culturas, lazer, estudos sociais, línguas estrangeiras, cuidados com a saúde, música, teatro, cultivo da terra, conto, ecologias, artesanatos, informática, potencializando o desenvolvimento da dimensão cognitivo e ao mesmo tempo afetiva e relativa dos alunos entre si e na sociedade.

Machado (2014) conclui que a educação integral não é, definitivamente, somente a ampliação do tempo escolar, mas, sobretudo, é a transformação da organização curricular de modo a refazer seus tempos e espaços e a reconhecer e valorizar as diferenças na escola, destacando que "é preciso uma mudança de pensamento, de políticas educacionais e, principalmente, de práticas pedagógicas que consolidem uma educação integral adequada" (MACHADO, 2014, p. 1).

Educação integral é um movimento que possibilita ao estudante perceber-se como pessoa que tem potencial para aprender, para participar do meio em que vive, de acordo com suas capacidades. Essa percepção tem efeito positivo na aprendizagem escolar e em sua vida pessoal e social.

Agregado ao conceito de educação integral observamos outros elementos que buscam dar materialidade a essa proposição, algumas vezes restringindo seus significados mais amplos como, por exemplo, a formulação do princípio de cidade educadora, divulgada pela Educação Cultura e Ação Comunitária (CENPEC): “A noção de educação integral se renova, agregando novos paradigmas como os da cidade educadora e instiga a ação conjunta entre escolas e demais espaços e organizações sócios culturais e esportivos, entre outras que operam no território". Apresentada como estratégia para a melhoria da qualidade na educação, ganha progressivamente a adesão do poder público bem como de diversos setores e organizações da sociedade civil. “Observa-se que estas últimas, desde a década de 1990, vêm apontando a perspectiva integral para a educação como estratégia para a garantia de direitos, 
proteção e inclusão social para crianças, adolescentes e jovens em situação de pobreza" (CENPEC, 2011, p. 35). Os autores destacam o conceito de "cidade educadora":

O conceito de Cidade Educadora teve origem em Barcelona, em 1990, a partir da 'Carta Inicial das Cidades Educadoras', estabelecendo princípios, valores e práticas pertinentes à atuação das instâncias governamentais, em especial a gestão municipal, no âmbito da organização e qualidade de vida das cidades e territórios onde os seres humanos se formam, trabalha e age politicamente. Esse documento foi atualizado em 1994 e novamente em 2004 para enfrentar três grandes desafios do século XXI: investir na educação de cada pessoa para que desenvolva seu potencial humano; promover as condições de igualdade e construir uma verdadeira sociedade do conhecimento sem nenhum tipo de exclusão. Em síntese, o conceito de cidade educadora visa à integração da oferta de atividades locais e culturais para potencializar sua capacidade educativa formal e informal. Seu lema é 'Aprender na cidade e com a cidade'. (CENPEC, 2011, p. 36).

A educação integral passa a ser vista como uma ação social, uma inclusão para os pobres como destaca os autores das publicações do CENPEC (2011), em que destacam a inclusão social como um dos objetivos centrais da proposta:

Ao priorizar a formação de crianças, adolescentes e jovens mais vulnerabilizados, a educação integral busca promover equidade e inclusão social por meio da educação. Também é compreendida como estratégia para aumentar a qualidade da educação e vencer o desafio de melhorar maciçamente o desempenho escolar dos estudantes brasileiros na educação básica. (CENPEC, 2011, p. 34).

Segundo Fernandes e Ferreira (2009), a proposta de se implantar uma política de Educação Integral partiu da análise dos baixos índices da educação básica. Surgiu, pois, da necessidade de melhorar a qualidade da educação, reduzindo o fracasso escolar e proporcionando às crianças e jovens novas possibilidades de se desenvolverem. A educação integral aparece como um novo desafio para a educação pública brasileira, levando em consideração que se vivenciam tempos de mudanças. Além disso, há que se considerar a complexidade da vida social contemporânea e as muitas e diferentes crises - de diferentes características - que perpassam a educação em nível nacional. Sendo assim, a possibilidade de se desenvolver este projeto nas escolas públicas encontra algumas limitações que dificultam o processo.

Na perspectiva de Guará (2009, p. 74),

As crianças e adolescentes precisam conhecer e reconhecer os símbolos e significados da cultura local e universal, entender a função social das instituições, dominar a língua e outros instrumentos da comunicação moderna, interpretar e compreender a vida prática, estabelecer e manter relações sócio afetivas, enfrentar conflitos e aprender a se situar no mundo como pessoas e como cidadãos. 
Tudo isso acontece, com mais ou menos intensidade, nos caminhos e roteiros de aprendizagem de sua vida cotidiana em seu bairro, em sua casa e na escola. Alguns terão portas abertas a esses conhecimentos; outros desenvolverão menos recursos para aprender e processar essa realidade, o que sempre constitui um desafio para a pesquisa e a intervenção educativa. Constitui se assim a ideia de aumentar o tempo na escola, ou seja, pensar a escola integral, oportunizando a todos uma educação de qualidade.

\section{Políticas públicas de educação integral}

Tecendo alguns apontamentos sobre a historicidade desse debate nas últimas décadas percebemos experiências anteriores que, no entanto, careceram de continuidade. Nesse cenário tem destaque as experiências desenvolvidas por Darcy Ribeiro na década de 1980, seguidor de Anísio Teixeira após a anistia foi eleito vice-governador do Rio de Janeiro na primeira gestão de Leonel Brizola. Foram criados até 1994 quinhentos Centros Integrais de Educação Pública (CIEPs), porém a implantação e a continuidade desses projetos não foram fáceis e, com passar dos anos foram sendo descaracterizados, pois além do custo elevado para o seu funcionamento, implantação da jornada para tempo integral e o compromisso com a proteção social, atendimento médico, odontológico e alimentação foram vistos como desvio do papel da escola.

Considerando os limites desse texto não aprofundaremos a análise dessas experiências, concentrando o enfoque nos normativos legais existentes e nas experiências mais recentes deles derivados. Considerando os dispositivos legais desde 1988 uma série de normativos garante a educação como um direito da criança e preveem a ampliação do atendimento escolar, como uma política a ser construída. Esses fundamentos podem ser encontrados na Constituição Federal de 1988, no Estatuto da Criança e do Adolescente (ECA) de 1990, na Lei Orgânica da Assistência Social (LOAS), Lei no 87.421 de 1993 e na Lei de Diretrizes de Bases da Educação (LDB), Lei no 9.394 de 1996.

Em 1988, com a Constituição Federal a assistência social foi posta ao lado da previdência social e de outras políticas públicas que buscam a superação do atendimento de urgência e a universalização dos direitos sociais a toda população. O exercício da cidadania aponta para uma educação integral na formação do ser humano em suas potencialidades, embora de forma vaga uma vez que o próprio conceito de cidadania é posto em disputa: ${ }^{4}$

A educação, direito de todos e dever do estado e da família, será promovida e incentivada coma colaboração da sociedade, visando ao pleno desenvolvimento da pessoa, seu preparo para o exercício da cidadania e sua qualificação para o trabalho. (BRASIL, 1988, p. 13). 
Com a elaboração do Estatuto da Criança e do Adolescente (ECA), no Art. 36, a criança e o adolescente têm direitos à educação, visando ao pleno desenvolvimento da pessoa, preparo para o trabalho e o exercício da cidadania, assegurando-lhes: igualdade de condições para acesso e permanência na escola; direito de ser respeitada por seus educadores; direito de contestar critérios avaliativos podendo percorrer as instancias escolares superior; direito de organização e participação em unidades estudantis; acesso à escola pública e gratuita próxima a sua residência (BRASIL, 1990).

Em 1993 a LOAS (BRASIL, 1993), no Artigo 24, define que os programas de assistência social compreendem ações integrantes e complementares com objetivo, tempo e área de abrangência definidos para qualificar, incentivar e melhorar os benefícios e os serviços assistenciais.

Em 1996 a LDB, Art. 34. Estabelece que a jornada escolar no ensino fundamental incluirá pelo menos quatro horas de trabalho efetivo em sala de aula, sendo progressivamente ampliado o período de permanência na escola.

$\S 1^{\circ}$ São ressalvados os casos do ensino noturno e das formas alternativas de organização autorizadas nesta Lei.

$\S 2^{\circ} \mathrm{O}$ ensino fundamental será ministrado progressivamente em tempo integral, a critério dos sistemas de ensino. (BRASIL, 1996, p.148).

Para dar uma ênfase no período de permanência do aluno na escola o Plano Nacional de Educação (PNE) lei nº13.005/2014 destaca a educação em tempo integral no mínimo em $50 \%$ (cinquenta por cento) das escolas públicas e atender, pelo menos $25 \%$ (vinte e cinco por cento) dos(as) alunos(as) da educação básica.

\section{O Programa "Mais Educação"}

O Programa "Mais Educação" foi instituído pela Portaria Interministerial n. 17/2007 e pelo Decreto Presidencial 7083/2010 e integra as ações do Plano de Desenvolvimento da Educação (PDE), como estratégia do Governo Federal para induzir a ampliação da jornada escolar e a organização curricular, na perspectiva da educação integral. A iniciativa é coordenada pela Diretoria de Educação Integral do MEC e secretarias estaduais e municipais de Educação. Sua operacionalização é feita por meio do Programa Dinheiro Direto na Escola (PDDE), do Fundo Nacional de Desenvolvimento da Educação (FNDE).

Fernandes e Ferreira (2012, p. 1), destacam alguns pontos em relação ao Programa "Mais Educação" a iniciativa do governo federal como uma estratégia para

[...] promover a educação integral no Brasil. Tem como objetivo desenvolver atividades sócio-educativas no contra turno escolar, na perspectiva de ampliar tempos, espaços, número de atores envolvidos no processo e 
oportunidades educativas em benefício da melhoria da qualidade da educação dos alunos brasileiros.

O programa mais educação visa fomentar, por meio de sensibilização, incentivo e apoio, projetos ou ações sócio educativo oferecido gratuitamente à criança, adolescentes e jovens e que considerem as orientações:

I. Contemplar a ampliação do tempo e do espaço educativo de suas redes e escolas, pautada pela noção de formação integral e emancipadora;

II. Promover a articulação, em âmbito local, entre as diversas políticas públicas que compõem o Programa e outras que atendam às mesmas finalidades;

III. Integrar as atividades ao projeto político-pedagógico das redes de ensino e escolas participantes;

IV. Promover, em parceria com os Ministérios e Secretarias Federais participantes, a capacitação de gestores locais;

V. contribuir para a formação e o protagonismo de crianças, adolescentes e jovens;

VI. Fomentar a participação das famílias e comunidades nas atividades desenvolvidas, bem como da sociedade civil, de organizações nãogovernamentais e esfera privada;

VII. Fomentar a geração de conhecimentos e tecnologias sociais, inclusive por meio de parceria com universidades, centros de estudos e pesquisas, dentre outros;

VIII. Desenvolver metodologias de planejamento das ações, que permitam a focalização da ação do Poder Público em territórios mais vulneráveis; e

IX. Estimular a cooperação entre União, Estados, Distrito Federal e Municípios. (BRASIL/MEC, 2012, p. 4).

Para que a escola pública seja inserida no Programa "Mais Educação" o diretor (a) da instituição precisa solicitar no site do MEC o Programa Direto na Escola Interativo (PDDE Interativo), em que existe um cadastro para preenchimento de dados pessoais e institucionais, que após uma análise feita pelo Ministério da Educação o responsável pela instituição receberá uma senha de acesso encaminhada pelo comitê de análise e aprovação da secretaria de educação de sua rede (município/estadual). Essas informações são passadas para o Instituto Nacional de Estudo e Pesquisas Educacionais (INEP) que confirma os dados e libera o cadastro de adesão ao Programa "Mais Educação". O programa estabelece os seguintes critérios para seleção das unidades escolares em 2012:

[...] - escolas contempladas com PDDE/Integral no ano de 2008, 2009,2010 e 2011 ;

- escolas estaduais, municipais e/ou distritais que foram contempladas com o PDE/Escola e que possuam o IDEB abaixo ou igual a 4,2 nas séries iniciais e/ou 3,8 nas séries finais;

- escolas localizadas nos territórios prioritários do Plano Brasil Sem Miséria;

- escolas com índices iguais ou superiores a 50\% de estudantes participantes do Programa Bolsa Família; 
- escolas que participam do Programa Escola Aberta; e escolas do campo. (BRASIL/MEC, 2012, p. 7).

Na perspectiva em que os programas são formulados, ficam distantes de uma proposta ampla de educação integral, uma vez que se propõe atender apenas os estudantes que não tem acesso a outros ambientes educacionais ou que estão com dificuldade de aprendizagem. Uma aparente contradição com os fundamentos da proposta uma vez que o ministério da educação recomenda às unidades executoras que selecionem os participantes de acordo com os seguintes critérios:

[...] - estudantes que apresentam defasagem idade/ano;

- estudantes das séries finais da $1^{\mathrm{a}}$ fase do ensino fundamental $\left(4^{\circ}\right.$ e/ou $5^{\circ}$ anos), onde existe maior saída espontânea de estudantes na transição para a $2^{\mathrm{a}}$ fase;

- estudantes das séries finais da $2^{\mathrm{a}}$ fase do ensino fundamental $\left(8^{\circ}\right.$ e/ou $9^{\circ}$ anos), onde existe um alto índice de abandono após a conclusão;

- estudantes de anos/séries onde são detectados índices de evasão e/ou repetência;

- estudantes beneficiários do Programa Bolsa Família (BRASIL/MEC, 2012, p. 9).

Nem todos os estados brasileiros dispõem de condições, tanto financeiras, como de espaço físico nas escolas de ensino regular, para oferecer aos alunos o contra turno, pois muitos não têm condições mínima para o atendimento ao ensino regular, o que dimensiona o desafio de ampliar a jornada escolar e o desafio ainda maior de fazer dessa ampliação uma proposta de formação integral dos sujeitos. Silva Filho (2013) destaca essas dificuldades ou mesmo a impossibilidade do desenvolvimento de um projeto como o "Mais Educação", que precisa de estrutura, no espaço escolar ou seu entorno. Conforme seu relato:

Propor uma educação integral com base nos conceitos de cidade educadora e territórios educativos no Brasil significa esquecer que em muitos bairros e cidades brasileiras, principalmente no norte e nordeste, o único equipamento publico existente é a própria escola, sendo a precariedade uma de suas marcas principais. Apelar para a oferta de espaços educativos por meio de redes da sociedade civil acaba sendo sinônimo de espaços precários para uma educação também precária (SILVA FILHO, 2013, p. 712).

A proposta do programa é promover a ampliação de tempos, espaços, e oportunidades educativas, compartilhando a tarefa de educar entre os profissionais da educação e de outras áreas, as famílias e diferentes atores sociais, sob a coordenação da escola e dos professores. No ano de 2010, o Programa Mais Educação estava presente em cerca de 10.000 escolas públicas, com IDEB abaixo da média nacional e localizadas em capitais, regiões metropolitanas e cidades com mais de 90 mil habitantes. 
$\mathrm{O}$ direito à diferença não pode ser entendido como o reconhecimento de algumas diferenças ou aquele que aponta para alguns estudantes como sendo os diferentes por não corresponderem à identidade dominante e convencional de estudante ideal. $\mathrm{O}$ direito à diferença vai além de abrir as portas das escolas, vai além do acesso ao seu ambiente educacional. Esse direito requer o questionamento de práticas que responsabilizam os estudantes pelo déficit e pelas dificuldades de aprendizagem, justificando a origem do fracasso escolar como sendo do estudante: "Por essa razão, a educação integral visa debater e ampliar a compreensão da comunidade escolar sobre a complexidade da diferença humana para, então, provocar outros modos de pensar e de fazer a escola" (MACHADO, 2014, p. 3).

Segundo escreve Guará (2009), sobre a política de educação integral como ação social, ou seja, a inclusão do cidadão na sociedade, muitas vezes o papel da escola é inserir novos conhecimentos e também oferecer o que seria o papel da família e da sociedade:

Educação integral com inclusão social supõe pensá-la articulada com as demais políticas sociais, rompendo a velha ordem que fragmenta saberes e necessidades - uma educação que constrói caminhos para um novo momento histórico de integração cada vez maior de conhecimentos e competências. Por isso as ações voltadas para a melhoria da educação contemporânea, seja na perspectiva quantitativa (atendimento a todos), seja na aposta qualitativa (todas as dimensões da vida), necessitam ser articuladas. Entretanto, o bom desempenho escolar continua a ser um direcionador fundamental para a inclusão cidadã. (GUARÁ, 2009, p. 68).

O programa Mais Educação é uma estratégia para ampliação da jornada escolar e a organização curricular na perspectiva da educação integral. As atividades são na área de educação ambiental, esporte e lazer, direitos humanos em educação, cultura e artes, promoção da saúde, comunicação e uso de mídias, investigação no campo das ciências da natureza e educação econômica.

Pensando na formação humana e conclui-se que existe a necessidade de uma educação de qualidade e que esta educação não se da só na escola; mas a escola tem que garantir a permanência dos sujeitos no período de sua formação, e eles devem reconhecer que além do tempo na escola, mesmo que seja em tempo integral existem outros ambientes que fazem parte da formação humana, por isso a necessidade da escola estar em constante diálogo com os outros ambientes de formação e principalmente as famílias.

Nas últimas décadas, o debate em torno da educação integral foi relegado a um segundo plano e limitado a algumas experiências regionais, provavelmente em função das graves lacunas quanto à universalização do acesso ao ensino fundamental. Assim, a proposição da educação integral enquanto política pública permaneceu, por muito tempo, 
destituída de maior importância ante um cenário em que o imprescindível direito à escolarização formal ainda se configurava, com razão, como meta prioritária. Conforme destaque das publicações das tendências: "Neste novo contexto político em que a sociedade exige a garantia de acesso à proteção e desenvolvimento pleno de crianças e adolescentes, a educação em tempo integral é alçada ao centro do debate da política pública" (TENDÊNCIAS, 2011, p. 22).

O desenvolvimento do programa mais educação deve estar em concordância com o ensino regular da instituição, para que possa ter resultados na melhoria da qualidade do ensino, como relata as publicações das tendências de educação integral. "É preciso manter em perspectiva a intencionalidade pedagógica, para que o conjunto das atividades desenvolvidas dialogue com o currículo escolar e corresponda a formação integral pretendida" (TENDÊNCIAS, 2011, p. 25). Assim, deve-se ter em vista o que se ensina e o que se aprende no tempo expandido e como gerir pedagogicamente esse tempo:

[...] integralidade significa, em essência, não fragmentação; educação integral significar pensar a aprendizagem por inteiro; as inter-relações entre atividades e propósitos precisam ser otimizadas e valoradas com base no currículo, no projeto político-pedagógico, numa clara intencionalidade pedagógica, que tenha a formação do sujeito e do seu direito de aprender como o grande ponto de chegada. (TENDÊNCIAS, 2011, p. 25).

Segundo Fernandes e Ferreira (2012 a implantação do programa de educação integral não é muito simples, é um processo demorado e que muitas vezes não consegue atender a demanda de alunos, considerando que não há vagas para que todos os alunos sejam inseridos. "Além disso, a estrutura física das escolas precisa ser modificada e ampliada para conseguir realizar as atividades propostas" (FERNANDES; FERREIRA, 2012, p. 6).

Trata-se, de um desafio a ser enfrentado no âmbito das políticas públicas. A implementação do Programa Mais Educação (ou outros programas similares) exige uma análise acurada acerca do ambiente escolar, além do compromisso de fazer as devidas modificações para que se possa realizar um trabalho pedagógico de qualidade. Investigar se de fato houve melhoria no rendimento dos alunos com este programa também é importante no sentido de possibilitar um redirecionamento de ações e/ou ampliação da oferta do programa na rede, com base em dados reais sobre sua eficácia.

\subsection{O Desenvolvimento do Programa "Mais Educação" no município de Dourados}

No município de Dourados o Programa foi regulamentado pela Resolução SEMED n ${ }^{\circ}$ 75/2013 (DOURADOS, 2013), legislação que acompanha a normatização nacional ao definir a Educação Integral como a ampliação da jornada escolar para, no mínimo, sete horas diárias, compreendidas por uma série de atividades 
[...] como acompanhamento pedagógico, experimentação e investigação científica, cultura e artes, esporte e lazer, cultura digital, meio ambiente, direitos humanos, práticas de prevenção aos agravos à saúde, promoção da saúde e da alimentação saudável, entre outras. (DOURADOS, 2013, s/p).

Segundo os documentos da secretaria de educação do município de Dourados as atividades a serem desenvolvidas no âmbito do Programa "Mais Educação" se organizam em torno de macrocampos como

[...] acompanhamento pedagógico, experimentação e investigação científica, cultura e artes, esporte e lazer, cultura digital, meio ambiente, direitos humanos, práticas de prevenção aos agravos à saúde, promoção da saúde e da alimentação saudável, entre outras. (DOURADOS,2013, s/p).

O programa é desenvolvido dentro das escolas ou em espaços sociais comunitários, mediada e articulada, por um professor comunitário como destaca o documento:

Para o desenvolvimento do PROGRAMA MAIS EDUCAÇÃO, além da Equipe Gestora composta pelo Diretor e/ou Diretor Adjunto e Coordenadores Pedagógicos da Escola, as escolas contarão com o Monitor e com o Coordenador do Programa, denominado Professor Comunitário. Parágrafo único: O Professor Comunitário deverá ser designado pela equipe gestora da Escola, com a anuência da Secretaria Municipal de Educação (DOURADOS, 2013, s/p).

Os monitores do Programa "Mais Educação" terão sempre o auxílio do coordenador pedagógico designado para o programa para orientar as suas ações que serão: planejar e ministrar as atividades, ser pontual, desenvolver atividades de acordo com as normas da instituição, executar projetos de acordo com a equipe escolar, participar de capacitações oferecidas pela secretaria de educação ou pela escola, avaliar o desenvolvimento dos alunos, controlar a frequência dos alunos e registrar tudo que ocorre durante o desenvolvimento das atividades. Nas escolas visitadas observamos que se desenvolvem atividades em várias áreas, com oficinas de letramento de português e matemática, judô, jornal, desenho, bale, futsal, fanfarra e reforço.

Ainda segundo a Resolução SEMED n 75/2013 (DOURADOS, 2013), o trabalho de monitoria deverá ser desempenhado, preferencialmente, por estudantes universitários de formação específica nas áreas de desenvolvimento das atividades ou pessoas da comunidade com habilidades apropriadas, como, por exemplo, instrutor de judô, mestre de capoeira, contador de histórias, agricultor para horta escolar, etc. Além disso, poderão desempenhar a função de monitoria, de acordo com suas competências, saberes e habilidades, estudantes da EJA e estudantes do ensino médio.

Entre outras funções desempenhadas dentro do programa destacamos a de Educador comunitário, direção escolar, oficineiro colaboradores e coordenador comunitário. 
De acordo com manual operacional do Programa Mais Educação disponibilizado pelo Ministério da Educação e Cultura (BRASIL, 2012) essas funções são assim organizadas:

Educador comunitário: Profissional da unidade escolar com disponibilidade de pelo menos 4 horas durante a semana (contrapartida da secretaria) e para atuar no final de semana. Responsável por organizar as atividades do Programa, dando suporte e orientação pedagógica às ações e integrando a escola com a comunidade.

Direção escolar: Responsável legal pela escola e, se presidente da UEx, pela assinatura do termo de compromisso e prestação de contas dos recursos. Acompanha e ajuda a garantir a gestão democrática, o planejamento e a organização coletiva e a integração do Programa com o Projeto Político Pedagógico da escola.

Oficineiro: Voluntário da comunidade do entorno, de outros locais ou de projetos parceiros com competência e habilidades específicas, responsável por desenvolver oficinas e atividades nos finais de semana para e com a comunidade. Suas atividades nos finais de semana podem ou não ser ressarcidas, de acordo com a necessidade para o desenvolvimento do seu trabalho.

Colaboradores: universitários, agentes de saúde, representantes de organizações comunitárias, culturais e da comunidade escolar.

Coordenador comunitário: Membro da comunidade com estreito vínculo estabelecido com a escola (por exemplo: responsável por aluno, integrante do Conselho Escolar etc.) e reconhecido como uma liderança, que tem a responsabilidade de coordenar as atividades no final de semana e integrar a comunidade com a escola.

Com a intenção de buscar informações sobre o desenvolvimento da educação integral as secretarias de educação criaram um comitê que tem como principal objetivo monitorar, acompanhar e compartilhar informações sobre o programa mais educação:

Os coordenadores dos Programas Mais Educação e Escola Aberta no âmbito dos Municípios, Estados e Distrito Federal deverão incentivar a criação de comitês territoriais. Estes comitês deverão ser constituídos pela representação de cada secretaria de educação estadual, municipal e distrital, por representantes de outras secretarias municipais, estaduais e distritais de áreas de atuação com interface nos Programas (Cultura, Esporte, Desenvolvimento Social e outras) universidades e atores sociais e institucionais diversos que colaboram para a realização das ações (representantes das Entidades Executoras - EEx - responsáveis pelo PDDE/Integral, Conselhos de Direitos da Criança e do Adolescente, diretor, professor comunitário, etc.). (MEC, 2012, p. 79).

No âmbito de nossa pesquisa aplicamos questionário a doze sujeitos selecionados a partir de seu envolvimento no programa, sendo seis monitores, três diretores e três 
coordenadores dos programas na unidade. Identificamos que os monitores não têm conhecimentos aprofundados sobre a dinâmica de funcionamento do programa, já os coordenadores relatam que conhecem o programa dominando os princípios de como ele funciona e o que ele oferece para as crianças.

Quando questionados sobre sua opinião sobre os pontos positivos e as dificuldades para a efetivação da proposta esses indivíduos apontam que percebem o programa como uma oportunidade da criança se socializar, desenvolver atividades diferenciadas no contra turno e ter auxílio nas dificuldades que encontra nas disciplinas do ensino regular. Identificam como dificuldades em seu funcionamento nas unidades escolares principalmente aquelas relacionadas à estrutura física inadequada e a falta de profissionais necessárias para desenvolver as oficinas que o programa oferece.

\section{Considerações finais}

Considerando a concepção histórica de educação integral como a formação do ser humano em todas as suas potencialidades, no sentido de uma formação mais ampla e profunda como apontou Gadotti (2009) observamos que o referido programa não se fundamenta nesses princípios, ao contrário, apresenta proposição focada nas crianças e adolescentes, que não tem condições financeiras ou que apresentam dificuldades de aprendizagem. Esses fazem cursos ou outras atividades fora da escola, como uma oportunidade de obter conhecimento e complementar o que aprendem no período regular, por meio de atividades lúdicas, esporte, dança, entre outros. Sem desmerecer a importância dessas atividades para aqueles que têm a oportunidade de frequentá-las consideramos que essas se dão no âmbito individual desses indivíduos, com fragilidades enquanto concepção das políticas educacionais.

A Educação Integral exige mais do que compromissos: impõe também e principalmente projeto pedagógico, formação de seus agentes, infraestrutura e meios para sua implantação. Ela será o resultado dessas condições de partida e daquilo que for criado e construído em cada escola, em cada rede de ensino, com a participação dos educadores, educando e das comunidades que podem e devem contribuir para ampliar os tempos e os espaços de formação das crianças, adolescentes e jovens na perspectiva de que o acesso à educação pública seja complementado pelos processos de permanência e aprendizagem.

Portanto, o programa em discussão apresenta uma concepção restrita de educação integral ao oferecer as atividades apenas para alguns, ou seja, crianças e adolescentes selecionados por critérios de renda ou rendimento escolar. Fica assim distante da ideia de uma 
educação com qualidade para todos com oportunidades de expandir conhecimentos, e proporcionar a todos o desenvolvimento máximo de suas potencialidades, se aproximando mais de uma proposta focalizada, e compensatória para os indivíduos identificados a partir de critérios de vulnerabilidade social, ou baixo rendimento escolar.

\section{REFERÊNCIAS}

BRASIL. Constituição da República Federativa do Brasil (1988). Brasília: Senado, 1998.

BRASIL. Estatuto da Criança e do Adolescente. Dispositivos Pertinentes a Lei no 8.069, 13 de julho de 1990. Legislação Correlata do Índice Temático. Brasília-DF. Edição impressa, 1990.

BRASIL. Lei n ${ }^{\circ}$ 9.394, de 20 de dezembro de 1996. Estabelece as diretrizes e bases da educação nacional. Diário Oficial da República Federativa do Brasil, de 23 de dezembro de 1996. Brasília: Poder Executivo, 1996.

BRASIL. Lei $n^{o} n^{o} 13.005$, de 25 de junho de 2014. Aprova o Plano Nacional de Educação PNE e dá outras providencias. Brasília: 2014. Disponível em: <www2amara.leg.br> Acesso em: 20 maio 2015.

BRASIL. Lei Orgânica da Assistência Social. Lei no 8.742/1993. Disponível em: <http://www.Assistenciasocial.al.gov.br/legislação/legislação-federal/loas.pdf.> Acesso em: 27 set. 2014.

BRASIL. Ministério da Educação e Cultura. Manual Operacional da Educação Integral. Brasília, DF: MEC, 2012.

BRASIL. Ministério da Educação e Cultura. Portaria Interministerial $n^{\circ} 17$, de 24 de abril de 2007. Institui o Programa Mais Educação. Brasília, DF: MEC, 2007c.

BRASIL. Ministério da Educação e Cultura. Texto Referência para o debate nacional. Série Mais Educação. Educação Integral. Brasília, DF: MEC, 2008.

BRASIL. Ministério da Educação e Cultura. Texto referência para o debate nacional. Série Mais Educação. Educação Integral. Brasília: MEC, 2009.

BRASIL. Ministério da Educação e Cultura. Decreto $n^{\circ}$ 7.083, de 27 de janeiro de 2010. Institucionaliza o Programa Mais Educação. Brasília: MEC, 2010.

BRASIL. Ministério da Educação e Cultura. Secretaria de Educação Continuada. Alfabetização e diversidade. Esplanada dos Ministérios. Disponível em: <http://www. portal.mec.gov.br/secad > Acesso em: 03 maio 2015.

CAVALIERE, A. M. V. Educação integral: uma nova identidade para a escola brasileira. Revista Educação \& Sociedade. Campinas, n. 81, dez./2002.

CUNHA, L. A. Educação, estado e democracia no Brasil. São Paulo: Cortez, 1995.

DOURADOS. Resolução SEMED n ${ }^{\circ}$ 075/2013. Institui o programa mais educação. Diário Oficial do Município, de 13 de agosto de 2013. Disponível em: http:< do.dourados.ms.gov.br/wp-content/uploads/2014/03/13-08-13.pdf>. Acesso em: 10 ago.2015.

FERNANDES, F. O.; FERREIRA, J. H. Educação em tempo integral: novos desafios para a educação no Brasil. Disponível em:

<http://funedi.edu.br/revista/files/numero3/n3\%25201semestre2012/7educacaoemtempointegr al.pdf> Acesso em: 07 jul. 2015. 
GADOTTI, M. Educação Integral no Brasil: inovações em processo. São Paulo: Instituto Paulo Freire. 2009. Disponível em:<http: acervo. paulofreire.org. > Acesso em: 27 set 2014

GUARÁ, I. M. F. R. Educação e desenvolvimento integral: Articulando saberes na escola e além da escola. Em Aberto, Brasília, v. 22, n. 80, p. 65-81, abr. 2009. Disponível em: http:// <www.emaberto.inep.gov.br/index.php/emaberto/article/view/.../1220>. Acesso em: 18 ago. 2014.

GONÇALVES, Antônio Sergio. Reflexões sobre educação integral e escola de tempo integral. Cadernos Cenpec, n. ${ }^{\circ}$ 2, Educação Integral, $2^{\circ}$ semestre 2006. Disponível em: http://<www.nexusassessoria.com.br>. Acesso em: 21/12/2014.

LECLERC, G. de F. E.; MOLL, J. Programa Mais Educação. Educar em Revista. Curitiba, n. 45. p. 91-110. jul/set, 2012. ed. UFPR.

MACHADO, R. Organização Curricular e as Diferenças na Escola na Perspectivas da Educação Integral. Congresso de educação básica (COEB). fev. 2014. Florianópolis, SC. Disponível em: <http://ptdocz.com/doc/453129/organiza\%C3\%A7\%C3\%A3o-curricular-eas-diferen\%C3\%A7as-na-escola>. Acesso em: maio 2015.

MOLL, J. et al. Caminhos da educação integral no Brasil. Porto Alegre: Penso, 2012.

MOLL, J. et al. Educação integral na educação básica e as matrizes históricas (2011).

Disponível em: <http: portal.mec.gov.br/enden.php?option-com_docmon\&tosk> Acesso em: 20 set. 2014.

SILVA, J. A. de A.; SILVA, K. N. P. A hegemonia às avessas no Programa Mais Educação. Revista Brasileira de Estudos Pedagógicos (online). Brasília, v. 94, n. 238, p. 701-720, set./dez. 2013.

SEDF. Secretaria de Estado de Educação do Distrito Federal. Educação Integral desafios e perspectivas. Disponível em:

<http://file:///D:/Documents/Documents/textos\%20para\%20pesquisa\%20do\%20tcc/Educa\%C 3\%A7\%C3\%A3o\%20Integral-desafios\%20e\%20perpectivas.html>. Acesso em: 05 out. 2014

TEIXEIRA, A. Educação não é privilégio. Rio de Janeiro: Ed. UFRJ. (Original publicado em 1957) Disponível em: <http:// www.s cielo.br/scielo.php?script=sci_arttex\&pid=s0103>. Acesso em: 27 set. 2014.

UNICEF. Tendências para a Educação Integral. São Paulo: Fundação Itaú Social CENPEC, 2011. Disponível em: 〈http:www.fundacaoitausocial.org.br〉. Acesso em: 18 ago. 2014.

Artigo recebido em: 04/04/2016

Artigo aceito em: 27/10/2017 